Southampton Eye Unit, Southampton General Hospital,

Tremona Road, Southampton SO16 6YD, UK

B Parkin

R Manners

Correspondence to: $\mathrm{Mr}$ Ben Parkin

benparkin@hotmail.com

Accepted for publication 23 June 2000

\title{
Aspirin and warfarin therapy in oculoplastic surgery
}

\author{
Ben Parkin, Ruth Manners
}

\begin{abstract}
Backgroundlaims-There are no nationally agreed guidelines on preoperative management of patients who are on aspirin or warfarin therapy. There is considerable evidence that complication rates in anticoagulated patients are low whereas there are higher rates of thromboembolic complications in those whose therapy is manipulated. This survey aimed to establish oculoplastic specialist and nonspecialist ophthalmic surgeons' current management practice of patients before oculoplastic surgery who are taking aspirin or warfarin and to assess the rate of complications in these patients.
\end{abstract}

Method-An anonymous postal questionnaire survey of all ophthalmic consultants and specialist registrars in the Wessex region along with oculoplastic specialists in the Southern region.

Results-The overall response rate was $\mathbf{9 2 \%}$. Preoperative management was influenced both by type of operation and by type of surgeon. A statistically significant higher proportion of surgeons would consider altering warfarin compared with aspirin treatment. For all procedures, non-specialists are unlikely to stop aspirin therapy, and are less likely to stop warfarin before all procedures apart from dacrocystorhinostomy. A significant proportion of surgeons $(18 \%)$ would allow insufficient time for the coagulation status of the patient to change after altering treatment. A considerable proportion of surgeons $(54 \%)$ reported that they had seen complications as a result either of stopping or continuing anticoagulation therapy.

Conclusions-In this survey, at least half the surgeons questioned would consider stopping warfarin before oculoplastic procedures. Over half of all surgeons have seen complications related to aspirin or warfarin, some of which were serious. A suggested approach to minimising patient risk is given.

(Br F Ophthalmol 2000;84:1426-1427)

There are no nationally agreed guidelines on the appropriate action to take preoperatively with patients on aspirin or warfarin therapy. In cataract surgery, the perioperative complication rate in such patients is low $(0-1 \%)^{1-5}$ and outcome is not adversely affected. ${ }^{6-9}$ Despite this, a significant proportion of surgeons discontinue such therapy before cataract surgery resulting in serious or fatal systemic thromboembolic complications in $4.5 \% .^{1-3}$

There are few data available, however, with respect to oculoplastic surgery. This survey was designed to establish how oculoplastic specialist and non-specialist ophthalmic surgeons manage patients on aspirin or warfarin therapy undergoing oculoplastic surgical procedures. It also aimed to establish the frequency of local and systemic complications in order to assess whether these patients are being put at risk by this practice.

\section{Methods}

A questionnaire was sent to all ophthalmic consultants and specialist registrars in the Wessex region (47) along with 15 oculoplastic specialists in the Southern region.

\section{Results}

The overall response rate was $92 \%$ and $100 \%$ of the oculoplastic specialists responded. For each question, the results indicate the percentage of the total replies received.

Overall, 93\% of surgeons did not mention that they would obtain advice before altering treatment and $74 \%$ did not specify that the indication for aspirin or warfarin would influence the decision to alter treatment.

The minimum period required in order to alter coagulation status before surgery is 7 days for aspirin and 3 days for warfarin. In those who gave an indication of their practice, aspirin was stopped an average of 10 days before surgery (range 2-30, SD 7 days). Warfarin was stopped an average of 3 days before surgery (range 1-10 days, SD 2 days). However, 18\% of surgeons volunteer that they would allow insufficient time for the coagulation status of the patient to change.

When responses for all surgeons are taken together, a statistically significant proportion (McNemar $\chi^{2}$ test) are more likely to stop warfarin rather than aspirin therapy before dacrocystorhinostomy (DCR) $(\mathrm{p}=0.0042)$, ptosis $(p=0.0015)$, entropion $(p=0.0026)$, and ectropion $(\mathrm{p}=0.0026)$. 
Table 1 Adjustment of treatment by oculoplastic specialists and non-specialists for different procedures. Numbers of surgeons who would sometimes or always stop treatment with percentage of total replies for each question

\begin{tabular}{|c|c|c|c|c|c|c|}
\hline & \multicolumn{3}{|c|}{ Non-oculoplastic specialists } & \multicolumn{3}{|c|}{ Oculoplastic specialists } \\
\hline & Stop aspirin & Stop warfarin & Heparinise & Stop aspirin & Stop warfarin & Heparinise \\
\hline Ectropion repair & $9(21 \%)$ & $20(50 \%)$ & $6(38 \%)$ & $6(40 \%)$ & $10(67 \%)$ & $2(40 \%)$ \\
\hline Entropion repair & $8(20 \%)$ & $19(48 \%)$ & $6(40 \%)$ & $6(40 \%)$ & $9(60 \%)$ & $2(40 \%)$ \\
\hline Ptosis procedures & $13(35 \%)$ & $25(69 \%)$ & $8(42 \%)$ & $8(57 \%)$ & $11(78 \%)$ & $3(50 \%)$ \\
\hline DCR & $23(57 \%)$ & $34(87 \%)$ & $12(48 \%)$ & $11(78 \%)$ & $11(85 \%)$ & $4(80 \%)$ \\
\hline
\end{tabular}

Table 2 Risk management for patients on aspirin and warfarin treatment undergoing oculoplastic procedres.

\begin{tabular}{ll}
\hline Indication & $\begin{array}{c}\text { Indication for aspirin and warfarin treatment should } \\
\text { always be taken into account in the decision to } \\
\text { alter treatment. Blanket preoperative protocols } \\
\text { should not be used. } \\
\text { Check INR is within therapeutic range and not } \\
\text { excessively high. } \\
\text { In many cases, it is preferable to operate despite } \\
\text { anticoagulation, or to reconsider the value of the } \\
\text { operation in view of the risks involved. } \\
\text { Reconsider }\end{array} \quad \begin{array}{c}\text { Sufficient time should be allowed for the coagulation } \\
\text { status of the patient to change (a minimum of } 3 \\
\text { days for warfarin and } 7 \text { days for aspirin). } \\
\text { In complicated cases, liaison with general medical or } \\
\text { haematological colleagues is essential. }\end{array}$ \\
Tharmacodynamics & $\begin{array}{c}\text { The use of heparin should be considered if warfarin } \\
\text { has to be discontinued. }\end{array}$ \\
Heparin &
\end{tabular}

For all procedures, non-specialists are unlikely to stop aspirin therapy (Table 1). Similar proportions of non-specialist and oculoplastic surgeons are likely to stop warfarin before a DCR ( $87 \%$ and $84 \%$ respectively). In contrast, fewer non-specialist than oculoplastic specialist surgeons sometimes or always stop warfarin before ptosis procedures $(69 \%$ and $78 \%$ respectively), entropion repair $(48 \%$ and $60 \%$ respectively), and ectropion repair (50\% and $67 \%$ respectively).

In those patients in whom warfarin therapy had been discontinued, around $40 \%$ of all surgeons would consider heparinisation of patients in those undergoing ectropion and entropion repair. This figure increases to approximately $50 \%$ before ptosis procedures and DCR. For oculoplastic specialists, the target maximum international normalised ratio (INR) before all procedures was approximately 3. For non-specialists, the target was similar prior to entropion and ectropion repair, but was 2.5 before DCR.

A considerable proportion of surgeons (54\%) reported that they had seen complications as a result of either stopping or continuing anticoagulation therapy.

\section{Discussion}

The preoperative management of oculoplastic patients on aspirin or particularly warfarin therapy presents a difficult clinical problem. There were no statistically significant differences in the approach taken by non-specialists compared with oculoplastic specialists.

The actual incidence of haemorrhagic complications compromising surgery in oculoplastic patients is unknown. In a study by Bartley ${ }^{10}$ on anticoagulated oculoplastic patients whose anticoagulation was not altered, no significant complications occurred. However, there are significant risks involved in discontinuing anticoagulation. ${ }^{11}$ In this survey, $54 \%$ of the surgeons reported that they had seen both haemorrhagic surgical complications and, in common with other surveys, ${ }^{1}$ serious systemic embolic complications including one death due to cerebrovascular accident and one brachial artery embolus. It is possible that such embolic complications were underreported.

In the case of cataract surgery, the available evidence suggests the practice of reducing aspirin and warfarin preoperatively is unnecessary and is putting patients at risk. Until data on haemorrhagic complication rates in oculoplastic patients on aspirin and warfarin are available, it is hard to justify a similar increase in the risk of serious life threatening complications. In view of this, a suggested approach for the management of such patients is given in Table 2 .

Ophthalmologists must not lose sight of known risks when trying to minimise perceived risks.

The authors would like to thank Joanna Vartan and Lorraine Low of the Research and Development Unit, Southampton General Hospital for help with this survey.

1 Stone LS, Kline OR Jr, Sklar C. Intraocular lenses and anticoagulation and antiplatelet therapy. Am Intra-Ocul Implant Soc 1985;11:165-8.

2 Moll AC, Van Rij G, Van Der Loos TLJM. Anticoagulant therapy and cataract surgery. Doc Ophthalmol 1989;72:36773.

3 Dick B, Jacobi FK. Cataract surgery and anticoagulation therapy. Klin Monatsbl Augenheilkd 1996;209:340-6.

4 Eke T, Thompson JR. The national survey of local Eke T, Thompson JR. The national survey of local
anaesthesia for ocular surgery. I. Survey methodology and current practice. Eye 1999;13(Pt 2):189-95.

5 Eke T, Thompson JR. The national survey of local anaesthesia for ocular surgery. II. Safety profiles of local anaesthesia techniques. Eye 1999;13(Pt 2):196-204.

6 Gainey SP, Robertson DM, Fay W, et al. Ocular surgery on patients receiving long-term warfarin therapy. $A m$ f Ophthalmol 1989;108:142-6.

7 Shuler JD, Paschal JF, Holland GN. Antiplatelet therapy and cataract surgery. $\mathcal{F}$ Cataract Refract Surg 1992;18:56771 .

8 Kammann J, Dornbach G, Linares I, et al. Lens implantation with patients on anticoagulation therapy. Ophthalmologe 1994;91:486-9.

9 Carter K, Miller KM. Phacoemulsification and lens implantation in patients treated with aspirin or warfarin. $f$ Cataract Refract Surg 1998;24:1361-4.

10 Bartley GB. Oculoplastic surgery in patients receiving warfarin: suggestions for management. Ophthalmic Plast Reconstr Surg 1996;12:229-30.

11 Gohlke-Barwolf C, Acar J, Burckhardt D, et al. Guidelines for prevention of thromboembolic events in valvular heart disease. Ad Hoc Committee of the Working Group on Valvular Heart Disease, European Society of Cardiology [see comments]. F Heart Valve Dis 1993;2:398-410. 